\title{
Educação empreendedora e negócios de impactos sociais: um estudo sobre o curso de Administração da Universidade Estadual de Santa Cruz, em Ilhéus, Bahia
}

Entrepreneurial education and social impacts business: a study on the Administration course of the

\author{
State University of Santa Cruz, in Ilhéus, Bahia
}

Educación emprendedora e impactos sociales empresas: un estudio del curso de Administración de la Universidad Estatal de Santa Cruz, en Ilhéus, Bahia

Recebido: 28/12/2020 | Revisado: 28/12/2020 | Aceito: 02/01/2021 | Publicado: 05/01/2021

\author{
Katianny Gomes Santana Estival \\ ORCID: https://orcid.org/0000-0002-3495-6356 \\ Universidade Estadual de Santa Cruz, Brasil \\ E-mail: ksgestival@uesc.br \\ Karine Nascimento Torquato \\ ORCID: https://orcid.org/0000-0001-5750-5278 \\ Universidade Estadual de Santa Cruz, Brasil \\ E-mail: karynetorquato@hotmail.com \\ Erliane Gomes dos Santos \\ ORCID: https://orcid.org/0000-0002-6474-1831 \\ Universidade Estadual de Santa Cruz, Brasil \\ E-mail: erliane.gomes98@gmail.com \\ Raiana Guimarães do Nascimento Fonseca \\ ORCID: https://orcid.org/0000-0001-8416-2952 \\ Universidade Estadual de Santa Cruz, Brasil \\ E-mail: raianaguimaraes2@gmail.com \\ João Carlos de Pádua Andrade \\ ORCID: https://orcid.org/0000-0002-0284-5651 \\ Universidade Estadual de Santa Cruz, Brasil \\ E-mail: jcpandrade@uesc.br
}

\begin{abstract}
Resumo
O debate acerca da educação empreendedora e negócios de impactos sociais tem ganhado ênfase nos últimos anos. São visualizados como um meio para desenvolver técnicas e alternativas para agregar valores tanto no âmbito econômico como no social. Esse artigo tem como objetivo analisar a prática da disseminação do conhecimento sobre o empreendedorismo, empreendedorismo social e negócios de impacto social no curso de administração da UESC, fazendo uma análise comparativa entre a grade curricular do curso de administração da UESC versus o curso de administração da Universidade de São Paulo (USP), e por fim uma análise do projeto pedagógico curricular (PPC) com o auxílio do coordenador do departamento do curso de administração da UESC. Assim essa pesquisa é predominantemente qualitativa, tem como delineamento de pesquisa bibliográfica, documental e empírica. Foi possível observar que existe uma relação frágil de disciplinas voltadas à educação empreendedora e negócios de impactos sociais na grade curricular do curso de Administração da Universidade Estadual de Santa Cruz. De acordo com as análises feitas no PPC e no sistema de disciplinas voltadas à educação empreendedora e negócios de impactos sociais não existem disciplinas específicas para a temática, mas algumas que podem ser consideradas como auxiliadoras do novo processo. Entre as conclusões, ressalta-se a importância do engajamento docente e alinhamento dos processos de ensino, pesquisa e extensão para que a educação empreendedora para os negócios de impacto seja efetiva na formação dos administradores, com base nos Princípios para a Educação e Gestão Responsável, propostos pela ONU em 2007.
\end{abstract}

Palavras-chave: Empreendedorismo; Negócios sociais; Administração.

\footnotetext{
Abstract

The debate about entrepreneurial education and social impact business has gained emphasis in recent years. They are seen as a means to develop techniques and alternatives to add values both in the economic and social spheres. This article aims to analyze the practice of disseminating knowledge about entrepreneurship, social entrepreneurship and social impact businesses in the UESC administration course, making a comparative analysis between the curriculum of the UESC administration course versus the UESC administration course. University of São Paulo (USP), and finally an analysis of the curricular pedagogical project (PPC) with the assistance of the coordinator of the department of the UESC administration course. Thus, this research is predominantly qualitative, with the design of bibliographic, documentary and empirical research. It was possible to observe that there is a fragile relationship between disciplines
} 
focused on entrepreneurial education and business with social impacts in the curriculum of the Administration course at the State University of Santa Cruz. According to the analyzes made in the PPC and in the system of disciplines aimed at entrepreneurial education and social impact businesses, there are no specific disciplines for the theme, but some that can be considered as assistants in the new process. Among the conclusions, the importance of teaching engagement and alignment of teaching, research and extension processes is emphasized so that entrepreneurial education for impact businesses is effective in training administrators, based on the Principles for Responsible Education and Management, proposed by the UN in 2007.

Keywords: Entrepreneurship; Social business; Administration.

\section{Resumen}

El debate sobre la educación emprendedora y las empresas de impacto social ha ganado protagonismo en los últimos años. Se ven como un medio para desarrollar técnicas y alternativas para agregar valores tanto en el ámbito económico como en el social. Este artículo tiene como objetivo analizar la práctica de difundir conocimientos sobre emprendimiento, emprendimiento social y empresas de impacto social en el curso de administración de la UESC, realizando un análisis comparativo entre el plan de estudios del curso de administración de la UESC versus el curso de administración de la UESC. Universidad de São Paulo (USP), y finalmente un análisis del proyecto pedagógico curricular (PPC) con la asistencia del coordinador del departamento del curso de administración de la UESC. Así, esta investigación es predominantemente cualitativa, con el diseño de investigación bibliográfica, documental y empírica. Se pudo observar que existe una relación frágil entre disciplinas enfocadas en la educación emprendedora y negocios con impactos sociales en el plan de estudios de la carrera de Administración de la Universidad Estatal de Santa Cruz. De acuerdo con los análisis realizados en el PPC y en el sistema de disciplinas orientadas a la educación emprendedora y las empresas de impacto social, no existen disciplinas específicas para el tema, pero sí algunas que pueden ser consideradas como asistentes en el nuevo proceso. Entre las conclusiones se destaca la importancia del compromiso docente y la alineación de los procesos de docencia, investigación y extensión para que la educación emprendedora para empresas de impacto sea efectiva en la formación de administradores, con base en los Principios de Educación y Gestión Responsable propuesto por la ONU en 2007.

Palabras clave: Emprendimiento; Negocio social; Administración.

\section{Introdução}

O debate sobre a educação empreendedora e negócios de impactos sociais têm ganhado ênfase nos últimos anos, visualizados como oportunidades para agregar valores, tanto no âmbito econômico quanto social e ambiental, dessa forma o debate amplia a participação também nas universidades.

Tendo em vista essa temática, esse artigo busca responder a seguinte pergunta: quais são os caminhos para aprimorar a carga horária e atividades complementares de conteúdos teóricos e práticos ligados à educação empreendedora e aos negócios de impactos sociais no curso de administração da UESC?

Dessa forma, esse trabalho tem como objetivo analisar a questão da educação empreendedora e os negócios de impactos sociais, no curso de administração da Universidade Estadual de Santa Cruz (UESC), por meio do levantamento das disciplinas voltado à execução de assuntos relacionados à educação empreendedora e negócios de impactos sociais; perfil dos professores; projeto pedagógico curricular (PPC); e por fim fazer uma análise comparativa da grade curricular do curso de Administração da UESC, com relação ao curso de Administração da Universidade de São Paulo (USP).

O curso de administração se mostra capaz de englobar tais características da educação empreendedora e negócios de impactos sociais, assim é relevante que esse levantamento sirva de subsidio para professores, planejadores e coordenadores de cursos para quando forem propor o PPC, elencar essas questões que tem ganhado ênfase no país no que tange ao ensino e ao mercado, e que possa colaborar para a formação do futuro profissional, e com ele trazer diferentes perspectivas para o mercado de trabalho.

\section{Metodologia}

Quanto aos aspectos metodológicos utilizados na construção desse artigo, foi construído a partir do método dedutivo que segundo Gil (2008) ele parte de princípios tidos como verídicos e busca levantar questionamentos lógicos acerca do não conhecido. A princípio realizou-se um levantamento bibliográfico com o auxílio de livros e artigos para identificar e 
caracterizar as definições dos temas tratados no referencial teórico, e o trabalho que já concretizou uma análise semelhante tendo como base a obra intitulada de "A contribuição das instituições de ensino superior para a educação empreendedora" dos autores Ricardo de Lima Ribeiro, Elvira Aparecida Simões de Araújo, Edson Aparecida de Araújo Querido Oliveira. Logo depois, foi executado também um levantamento documental acerca dos dados das disciplinas vigentes nos cursos de administração da UESC e USP, que serviu de suporte para realizar uma análise comparativa entre ambas.

Por fim foi feita uma consulta ao PPC que estava em revisão pelo colegiado de administração da UESC, com a presença e aval do coordenador do curso no dia 10 de dezembro de 2019, nessa etapa foram formuladas seis questões para verificar quais alterações estavam sendo feitas no PPC e se essas iriam adicionar ao curso mais conteúdos relacionados à educação empreendedora e aos negócios de impacto social.

O trabalho tornou-se único, pois é um dos precursores no que diz respeito à análise da grade curricular quanto aos conteúdos de educação empreendedora e negócios de impacto social. Essas etapas constituíram um estudo de caso que de acordo com Pereira, Shitsuka, Parreira e Shitsuka (2018) caracteriza-se como uma descrição e análise o mais detalhada possível de algum caso que apresente alguma particularidade que o torna especial. Ele foi fruto do método qualitativo, pois é possível verificar que houve uma análise crítica fruto da interpretação dos autores, das tabelas e respostas dos questionamentos.

Esse artigo encontra-se subdividido em quatro fases, que consistem respectivamente na revisão de literatura, apresentação das características do curso de administração da UESC, análise comparativa entre o curso de administração da UESC e USP, análise das respostas da entrevista, e finda com as discussões acerca das considerações finais.

\section{Educação Empreendedora}

De acordo com Lopes e Lima (2019) a Educação Empreendedora (EE) pode ser vista como uma importante ferramenta aceleradora do processo de formação do indivíduo quanto empreendedor. No entanto, o mesmo necessita de uma melhor formulação de acordo com as etapas, um meio que estude e comprove sua eficiência e eficácia no processo de disseminação do conhecimento, tanto no quesito teórico como no prático. Por fim, acrescenta a fraca participação de artigos publicados em revistas bem nomeadas, e destaca que esse é um longo caminho a seguir e aprimorar para poder realmente chegar a uma solução acerca de educação empreendedora.

Em consonância Krugüer, Büger e Minello (2019), abordam que a educação empreendedora pode ser vista como uma função importante que é a - auxiliar alunos a desenvolverem conhecimento em determinadas áreas e que no futuro essas ações possam colaborar com o crescimento econômico e social de um país, isso pode se resultar através da implantação e ampliação de ações educadoras em escolas de nível médio, e até mesmo em universidades.

Ademais de acordo com Krugüer, Büger e Minello (2019) apud Cope (2005) apontam que a educação empreendedora pode ser entendida como: Um processo dinâmico de conscientização, associação e aplicação que envolve transformar as experiências e conhecimento aprendidos em resultados funcionais. Ou seja, ninguém nasce empreendedor, o empreendedorismo ele tende a ser desenvolvido ao longo de sua formação, e principalmente no âmbito universitário, e que deve haver um plano pedagógico que incentivem o empreendedorismo como, por exemplo, palestras, recomendações de leituras, estudos de casos, visitas em empresas, simulações e projetos desenvolvidos em grupos.

Com relação à definição do empreendedor, (Martin \& Osberg, 2018) conceituam empreendedor como pessoas extraordinárias que têm ideias brilhantes, que criam novos produtos e serviços, que melhoram positivamente a vida das pessoas, e que impulsionam a mudança social, e é esse retorno potencial, com seu benefício transformador e duradouro para a sociedade, define o campo e seus praticantes separados. O mesmo aponta que existe certa diferença entre empreendedor $x$ empreendedor social.

$\mathrm{Na}$ caracterização do empreendedor social descreve que é aquele que busca valor na forma de benefícios 
transformacionais em grande escala que se acumulam em um segmento significativo da sociedade, que tem como proposta de valor a população carente, negligenciada ou altamente desfavorecida que não tem meios financeiros ou influência política para alcançar o benefício transformador por conta própria. Os empreendimentos criados por empreendedores sociais podem certamente gerar renda, e podem ser organizados como sem fins lucrativos ou com fins lucrativos (Martin e Osberg, 2018).

\section{Negócios de Impactos Sociais}

De acordo com Silva e Lizuka (2018) os Negócios Sociais (NS):

Os NS são organizações que buscam, ao mesmo tempo, resultados econômico-financeiros, impacto social e ambiental positivos, ou seja, não se trata de uma empresa tradicional com responsabilidade social, pois sua missão está ligada essencialmente à geração de alguma forma de impacto positivo na sociedade. (p.4)

Walchhütter e Lizuka (2019) acrescentam que nesses tipos de negócios existe um comprometimento social atingido através de atividades comerciais por meio da oferta de produtos e serviços. Um NS é um modelo de negócio diferente dos tradicionais isso porque ele auxilia na criação de inovação. Mas, essa inovação é diferente das outras, pois através dela será possível solucionar alguns dos problemas da sociedade (Cury e Miguel, 2017).

A visão de Walchhütter e Lizuka (2019) apud Bornstein e Davis (2010) aponta que Negócios Sociais são os resultados do Empreendedorismo Social, onde as pessoas constroem ou modificam organizações com o objetivo de solucionar os problemas sociais. Dessa forma Barki, Comini, Cunliffe, Hart e Rai (2015) acrescentam que existe uma grande relação entre empreendedorismo social, negócios sociais e negócios de impactos sociais. Sendo que todos usam um modelo financeiro sustentável, que geram um impacto social.

Cury e Miguel (2017) expõem três perspectivas ligadas aos negócios sociais. A europeia, a norte-americana e a dos países emergentes ou em desenvolvimento. Na perspectiva europeia, o termo mais utilizado é o de empresa social, e tem como foco a parte marginalizada da sociedade e visa também causar um impacto social. A norte-americana utiliza o termo negócios sociais, geralmente é caracterizada como uma empresa com o foco social, e causar um impacto social e financeiro é o seu maior objetivo. A perspectiva dos países emergentes ou em desenvolvimento utiliza o termo negócios inclusivos, preocupa-se com a diminuição da pobreza no meio social e com a inclusão neste. E assim, como a visão europeia o seu foco é o causar um impacto social.

De acordo com Silva e Lizuka (2018) os negócios de impactos sociais apresentam pontos ligados ao bem ambiental e social, e a obtenção de lucro. Outros termos que são semelhantes aos de negócios sociais serão expostos no quadro a seguir. 
Quadro 1. Termos e definições.

\begin{tabular}{|c|c|}
\hline TERMOS & DEFINIÇão \\
\hline Empresa Social & $\begin{array}{r}\text { É um negócio onde os excedentes do dinheiro } \\
\text { recebido com as suas vendas de bens ou serviços, são } \\
\text { aplicados em áreas que tragam benefícios para a sociedade } \\
\text { ou no próprio negócio. }\end{array}$ \\
\hline Negócios Inclusivos & $\begin{array}{r}\text { Tem o foco de gerar emprego e renda para a parte } \\
\text { marginalizada da população que habitam em locais de } \\
\text { riscos ambientais e sociais. }\end{array}$ \\
\hline Negócios com Impacto Social & $\begin{array}{c}\text { É um modelo híbrido de organização que mistura } \\
\text { pontos do segundo setor (privado) e do terceiro setor } \\
\text { (gestão social). }\end{array}$ \\
\hline Negócios da Base da Pirâmide & $\begin{array}{c}\text { É um modelo que auxilia a população pobre a } \\
\text { melhorar a sua qualidade de vida, através do fornecimento } \\
\text { de subsídio para pessoas que possuem baixa renda. }\end{array}$ \\
\hline Empresa B Corp & $\begin{array}{c}\text { É aquela que possui certificação do Sistema B, são } \\
\text { empresas que tem fins lucrativos e que são certificadas pelo } \\
\text { Laboratório B. }\end{array}$ \\
\hline
\end{tabular}

Elaboração dos autores. Fonte: Silva e Lisuka (2018).

\section{Curso de administração da Universidade Estadual de Santa Cruz}

De acordo com o colegiado do curso de administração da UESC, o curso tem duração de oito semestres. O objetivo central deste é formar empreendedores e administradores que tenham responsabilidade com a sociedade, por conta do crescente desaparecimento das vagas de trabalho e da elevação da participação das pessoas na responsabilidade social. O administrador deve ter uma visão estratégica, capacidade de investigação e um pensamento crítico sobre a atualidade. O curso tem como missão: "Formar administradores buscando o perfil de líderes e empreendedores com competência profissional, capazes de tomar decisões apresentando flexibilidade intelectual e adaptabilidade contextualizada, atentos às tendências do mercado e aos valores de responsabilidade social, justiça e ética profissional". (p.1). O departamento de administração da UESC é composto por quinze professores, sendo que sete são doutores e oito são mestres.

\section{Curso de Administração da Universidade de São Paulo}

De acordo com a Faculdade de Economia e Administração (FEA) USP (2019) o departamento de administração surgiu no início dos anos 60 e era composto por disciplinas integradas do curso de contabilidade e economia. O curso tem duração de oito semestres, com carga horária obrigatória de aula de 1980 e de trabalho de 660.

Eles têm como visão se tornar o curso com o maior nível de competência do Brasil para formar indivíduos líderes, que possam administrar as organizações de uma maneira diferenciada, e assim ajudar a construir uma sociedade melhor (FEA/USP, 2019). Sua missão é propiciar aos alunos de Administração uma formação que lhes dê a possibilidade de se tornar os profissionais mais reconhecidos do Brasil, assim como, proporcionar-lhes um pensamento crítico e conceitual que lhes dê a chance de continuar se aperfeiçoando a cada dia (FEA/USP, 2019). 


\section{Análise dos Projetos Acadêmicos Curriculares}

A partir da identificação das disciplinas que compõem a grade curricular do curso de administração das universidades estudadas, e das respostas dadas pelo diretor do curso de administração da UESC, elaboramos o seguinte quadro elencando as disciplinas específicas com abordagem para o empreendedorismo e negócios de impactos sociais. Foi possível identificar a implantação da disciplina optativa "Inovação Social e Empreendedorismo Social na Prática", na USP, ofertada atualmente (no ano de 2020) na modalidade EAD.

Quadro 2. Análise comparativa das disciplinas de administração (UESC e USP).

\begin{tabular}{|c|c|}
\hline UESC & USP \\
\hline Administração mercadológica (OB) & Comportamento organizacional (OB) \\
\hline Elaboração de projetos (OB) & Decisões de produtos, serviços e preços (OB) \\
\hline Administração estratégica (OB) & Planejamento estratégico (OB) \\
\hline Ética profissional e negócios (OB) & Gestão de pessoas (OB) \\
\hline Comunicação empresarial (OB) & Estrutura e análise de mercados (OB) \\
\hline Organização, sistemas e métodos (OB) & Gerenciamento de projetos (OB) \\
\hline Jogos empresariais (OB) & Cultura e Poder nas organizaçõos (OP) \\
\hline Teoria Geral da Administração III & Sistemas de Informações Empresariais e Negócios Digitais \\
$($ OB) & (OP) \\
\hline Tópicos Emergentes (OB) & Modelo de Negócios (OP) \\
\hline Gestão do Desenvolvimento Regional & Desenvolvimento de novos negócios (OP) \\
\hline (OB) & Empreendedorismo e Inovação (OP) \\
\hline Políticas Públicas e Cidadania (OB) & Inovação Social e Empreendedorismo Social na Prática (OP) \\
\hline
\end{tabular}

*OB: disciplinas obrigatórias; *OP: disciplinas optativas.

Elaboração dos autores. Dados a partir da grande curricular dos cursos.

Percebe-se que apenas a USP possui uma disciplina específica que trata as questões da inovação e empreendedorismo social. Através do estudo da ementa foi possível identificar que o curso de Administração da USP implantou a disciplina com base na adoção ao protocolo internacional que estabelece o compromisso com a formação em práticas responsáveis de gestão Principles for Responsible Management Education (www.unprme.org) (UNPRME, 2020).

Os Princípios para a Educação de Gestão Responsável (PRMEs) são uma iniciativa das Organização das Nações Unidas (ONU), propostos no ano de 2007. Visam elevar o perfil da sustentabilidade em escolas ao redor do mundo, o com foco no desenvolvimento dos estudantes de negócios de hoje para que desenvolvam e promovam as capacidades para promoverem as mudanças futuras. O programa visa orientar as escolas de negócios e gestão para garantirem a formação dos futuros líderes com as habilidades necessárias para equilibrar as metas econômicas e de sustentabilidade, com atuação alinhada aos Objetivos de Desenvolvimento Sustentável (ODS). É uma iniciativa voluntária que tem mais de 800 parceiros no mundo e se tornou a maior articulação entre as Nações Unidas e as instituições globais de ensino superior relacionadas à gestão (UNPRME, 2020).

De acordo com as informações disponíveis no site da Faculdade de Economia e Administração da USP (USP, 2020, 
p.1 e 2), a disciplina Inovação Social e Empreendedorismo Social na Prática (OP) é assim descrita: "O escopo desta disciplina insere-se nesse objetivo de propiciar conhecimentos teóricos e práticos que propiciem aos alunos de graduação o desempenho profissional responsável e estimulem em alunos de ensino médio o empreendedorismo com finalidades socioambientais."

\section{E tem como objetivos:}

Introduzir o referencial teórico-conceitual que dá suporte aos temas: Inovação Social e Empreendedorismo Social;

Desenvolver competências empreendedoras em alunos de graduação e alunos de ensino médio;

Estruturar iniciativas e soluções para problemas socioambientais.

\section{Programa:}

Aulas teóricas sobre tópicos em empreendedorismo e inovação social: Design Thinking, modelo de negócios, prototipação, ecossistema da inovação, oficinas técnicas para alunos de ensino médio:

Oficina 1: O que é empreendedorismo?

Oficina 2: Primeira roda de conversa com empreendedores sociais sobre o início da jornada empreendedora

Oficina 3: Como pensar de forma inovadora?

Oficina 4: Como construir soluções inovadoras?

Oficina 5: O que é empreendedorismo social?

Oficina 6: Modelo de Negócios

Oficina 7: Como criar e desenvolver seu produto?

Oficina 8: Captação de recursos e ecossistema empreendedor

Oficina 9: Roda de conversa com empreendedores sociais sobre desafios de gestão

Oficina 10: Pitch e técnicas de oratória

Oficina 11: Preparação dos grupos para evento de encerramento

Evento de Encerramento: apresentação das soluções na FEA para avaliação de uma banca. (USP, p.1 e 2, 2020).”

A análise realizada sinalizou que a USP possui uma disciplina que aborda de forma específica na teoria e prática o contexto do empreendedorismo e negócios de impacto social e treze disciplinas que abordam nas suas ementas descritas e disponíveis na análise documental realizada no mês de novembro de 2019 as temáticas do empreendedorismo, impacto social, inovação social e/ou negócios de impacto social. Enquanto no curso de Administração da Universidade Estadual de Santa Cruz, em Ilhéus, Bahia não há nenhuma disciplina específica que aborda o empreendedorismo e/ou negócios de impacto social, apesar de identificadas na análise do PPC, onze disciplinas que nas suas ementas, permeiam a temática do empreendedorismo.

Com a consideração do contexto específico do curso de Administração, da Universidade Estadual de Santa Cruz, em Ilhéus/Bahia, durante a consulta direta ao coordenador do curso de Administração da UESC, no mês de dezembro do ano de 2019, com o intuito de analisar da melhor maneira possível o PPC que estava sendo elaborado, foram verificados seis pontos que serão expostos em forma de perguntas e respostas a seguir:

i) Quais principais disciplinas estão relacionadas com a educação empreendedora e negócios de impactos sociais no curso?

R: Teoria Geral da Administração III; Tópicos Emergentes; Gestão do desenvolvimento regional; e políticas públicas e cidadania.

ii) Quais principais dificuldades que você ver ao implantar um novo PPC? 
R: A participação dos professores no processo de construção.

iii) Os professores do departamento estão de acordo com o novo método?

R: A princípio sim, ou somente os que participam.

iv) Quais as principais vantagens em incluir uma maior carga de disciplinas voltadas para a questão do empreendedorismo e os negócios de impactos sociais?

R: Torna a formação do profissional mais voltado para as novas perspectivas de mercado que estão surgindo.

v) No contexto regional entorno da universidade existe a possibilidade de tornar as disciplinas mais práticas? Se sim de qual forma? Se não qual o motivo?

R: Sim, por meio da gestão e o estímulo de negócios, da vivencia empresarial, e questões de estágios, consultorias, demais atividades práticas, adoção de mais tecnologias e a curricularização da extensão.

vi) Dentre as optativas levantadas de outros cursos quais se caracterizam como mais importantes para a construção desse novo PPC considerando o empreendedorismo e negócios de impactos sociais para a sociedade?

R: gestão de projetos; gestão de conhecimento e inovação; lazer, turismo e sistema mundial hoteleiro; economia rural; administração rural; administração rural e agronegócio; análise e gestão de novos modelos de negócios.

A partir dessa análise, foi possível identificar que as disciplinas as ligadas ao tema educação empreendedora, não são totalmente direcionadas para esse campo. E a maioria delas não iriam explorar o tema de maneira ampla, com a consideração dos campos de atuação do Administrador nos setores privado, público, negócios de impacto e terceiro setor. Outro ponto importante é que uma das dificuldades, no momento da implantação de um novo PPC é a colaboração e a participação do corpo docente como um todo.

A análise do corpo docente também evidenciou que mais de 50\% dos quinze docentes ativos no curso de Administração possuem produções científicas, técnicas e profissionais nas áreas do empreendedorismo, empreendedorismo social, negócios de impacto e inovação social, o que sinaliza que a capacidade acadêmica e profissional dos docentes deve ser melhor otimizada nos processos de ensino aprendizagem.

Quando foi estudada sobre a questão das disciplinas de outros cursos que eram voltadas ao tema central do trabalho, foram expostas algumas que aparentemente tinham mais conteúdo voltado a esse tema, como é o caso da disciplina gestão de conhecimento e inovação, do curso de Engenharia de Produção, que também tem no seu Projeto Acadêmico Curricular (PAC) outras disciplinas que são ligadas a esse tema, como a de Empreendedorismo, ofertada especificamente para os cursos das Engenharias.

Com a consideração do contexto de demandas por geração de emprego, renda e soluções para os problemas sociais e ambientais, que também gerem recursos financeiros para a escalabilidade e da mobilização internacional das escolas de gestão através da adesão aos "Princípios para Educação de Gestão Responsável (PRME, 2020)" ; para que o problema seja solucionado, é preciso que o curso de Administração na perspectiva do longo prazo crie uma disciplina específica para a educação empreendedora e negócios de impacto.

Outra possibilidade em curto prazo seria o aumento da carga de conteúdo direcionada a educação empreendedora, nas disciplinas que foram expostas e que estão presentes no curso de Administração e em outros cursos da UESC.

Engajar os docentes do próprio departamento é um ponto de grande importância, já que a maioria (mais de 50\%) já atuam no empreendedorismo e negócios de impacto nos pilares da pesquisa e extensão. Aproximar a pesquisa e extensão dos processos de ensino aprendizagem é uma estratégia viável para o curso de Administração, com foco na melhoria da qualidade e atendimento das novas demandas do mercado e sociedade. 


\section{Conclusão}

Pode-se concluir que apesar da presença e do crescimento do debate acerca do empreendedorismo, negócios de impacto e da educação empreendedora no Brasil, é necessária a formulação pedagógica que influencie e desperte os estudantes para serem inovadores/empreendedores, o que não é apenas um problema que afeta a universidade a qual foi desenvolvida a pesquisa, mais sim em âmbito nacional. Envolver docentes, comunidade e organizações privadas, públicas e não governamentais no processo da formação empreendedora para o impacto social é uma estratégia possível de implantação, quando o ensino, pesquisa e extensão acontecem de forma integrada.

Como sugestão de trabalhos futuros foi percebida a possibilidade e a necessidade de desenvolver a análise metodológica de outros cursos de graduação e também sobre as perspectivas dos alunos e egressos com relação à educação empreendedora e os negócios de impacto social.

Os resultados deste artigo demonstraram que ainda existe uma escassez de disciplinas voltadas a este assunto, tanto em instituições reconhecidas e que estão no topo dos rankings de ensino, como nas instituições novas e que ainda estão se consolidando no cenário do ensino brasileiro.

A implementação de uma disciplina específica que aborda o empreendedorismo e inovação social no curso de Administração da USP, sinaliza a importância que as instituições de menor porte e de outras localidades, considerarem a análise da sua experiência e das melhores práticas para que possam criar disciplinas optativas que se atendam às novas realidades dos negócios de impacto, formar administradores com a visão de negócios, mas também com a perspectiva de otimização dos resultados econômicos, sociais e ambientais para a redução das desigualdades.

Apesar da análise documental preliminar das informações disponíveis sobre os projetos de pesquisa e extensão referentes às temáticas sobre o empreendedorismo e negócios de impacto, vale sinalizar que mesmo que os temas não estejam formalizados nas disciplinas e projetos acadêmicos curriculares, eles são executados na formação dos estudantes através dos pilares da pesquisa e extensão, na Universidade Estadual de Santa Cruz (UESC) e USP, o que reforça a importância do aprofundamento das discussões em trabalhos futuros, que podem ser tratado a partir de uma pesquisa/entrevista com os discentes em formação sobre as perspectivas, e também com os egressos do curso a respeito de sua formação profissional.

Esse trabalho foi elaborado com o seguinte percentual de participação de cada autor: Katianny Gomes Santana Estival 25\%, Karine Nascimento Torquato 25\%, Erliane Gomes dos Santos 25\%, Raiana Guimarães do Nascimento Fonseca $10 \%$. João Carlos de Pádua Andrade 15\%.

\section{Referências}

Araújo, E. A. S., \& Oliveira, E. A. A. Q. (2012). A contribuição das instituições de ensino superior para a educação empreendedora. The 4th International Congress on University-Industry Cooperation. Taubaté, SP, Brasil. https://www.unitau.br/unindu/artigos/pdf387.pdf.

Barki, E., Comini, G., Cunliffe, A., Hart, S., \& Rai, S. (2015). Empreendedorismo Social e Negócios Sociais: Retrospectiva e Pesquisa Prospectiva. https://rae.fgv.br/sites/rae.fgv.br/files/social_entrepreneurship_and_social_business_retrospective_and_prospective_research_0.pdf.

Cury, D. P., \& Miguel, L. A. P. (2017). A importância dos negócios sociais na geração de valor para a sociedade dentro da ótica de liberdades econômicas. Centro de Liberdade Sconômica Paulo. https://www.mackenzie.br/fileadmin/OLD/62/ARQUIVOS/PUBLIC/SITES/ECONOMICA/2017/A_importancia_dos_negocios_sociais_na_geracao_de_valor _social_30out2017_artigo.pdf.

Gil, A. C. (2008). Métodos e técnicas de pesquisa social. (6a ed.). Atlas.

Krugër, C., Burger, R. E., \& Minello, I. F. (2019). O papel moderador da educação empreendedora diante da intenção empreendedora. Revista Economia e Gestão, 19 (52). http://200.229.32.55/index.php/economiaegestao/article/view/18224/14852.

Lopes, R. M. A., \& Lima, E. (2019). Desafios atuais e caminhos promissores para a pesquisa em empreendedorismo. Revista de Administração de Empresas, v. 59 (4). http://bibliotecadigital.fgv.br/ojs/index.php/rae/article/view/80001/76461.

Martin, R. L., \& Osberg, S. (2007). Empreendedorismo Social: O Caso para Definição. Revista: Stanford Social Innovation Review. Estados Unidos. https://ssir.org/articles/entry/social_entrepreneurship_the_case_for_definition. 
Research, Society and Development, v. 10, n. 1, e13410111546, 2021

(CC BY 4.0) | ISSN 2525-3409 | DOI: http://dx.doi.org/10.33448/rsd-v10i1.11546

Pereira, A. S., Shitsuka, D. M., Parreira, F. J., \& Shitsuka, R. (2018). Metodologia da pesquisa científica. Santa Maria: Núcleo de Tecnologia Educacional NTE. https://repositorio.ufsm.br/bitstream/handle/1/15824/Lic_Computacao_Metodologia-Pesquisa-Cientifica.pdf?sequence=1.

Silva, S. C., \& Lisuka, E. S. (2018). Mapeamento de negócios sociais e organizações congêneres no Brasil. Revista de Ciência da Administração, 20 (52).https://periodicos.ufsc.br/index.php/adm/article/view/2175-8077.2018V20n52p123/pdf.

Walchhütter, S., \& Lisuka, E. S. (2019). Tensões organizacionais inerentes como elemento distinto a natureza dos negócios sociais. Revista de Ciência da Administração, 21 (53). https://periodicos.ufsc.br/index.php/adm/article/view/2175-8077.2019V21n53p129/pdf.

Universidade Estadual de Santa Cruz. (2019). Colegiado de administração. http://www.uesc.br/colegiado_administracao/index.php.

Universidade de São Paulo. (2019). Faculdade de Economia, Administração e Contabilidade. https://uspdigital.usp.br/jupiterweb/listarGradeCurricular?codcg=12\&codcur=12012\&codhab=1\&tipo=N

Universidade de São Paulo. (2020). Faculdade de Economia, Administração e Contabilidade. https://www.fea.usp.br/administracao/graduacao/disciplinas?p=8.

Principles for Responsible Management Education. (2020). Unprme how to engage? https://www.unprme.org/how-to-engage. 